\title{
BRAF V600E mutation and KRAS codon 13 mutations predict poor survival in Chinese colorectal cancer patients
}

\author{
Jing Chen ${ }^{1}$, Fang Guo ${ }^{1}$, Xin Shi ${ }^{3}$, Lihua Zhang ${ }^{2}$, Aifeng Zhang ${ }^{2}$, Hui Jin ${ }^{4}$ and Youji He ${ }^{1^{*}}$
}

\begin{abstract}
Background: Mutations in KRAS, BRAF and PIK3CA are the most common somatic alterations found in the colorectal cancer (CRC) patients from Western countries; but their prevalence and prognostic value have not been adequately assessed in Asian patients. The aim of this study was to determine the mutation frequencies of these genes in Chinese CRC patients and to investigate their impact on prognosis.

Methods: The sequences of exon 2 of KRAS, exon 15 of BRAF and exons 9 and 20 of PIK3CA were evaluated by PCR and direct sequencing using DNA extracted from formalin-fixed paraffin-embedded (FFPE) tissues from primary CRC tumors of 214 patients (colon/rectum: 126/88).

Results: KRAS, BRAF and PIK3CA mutations were identified in 44.9\% (96/214), 4.2\% (9/214) and 12.3\% (26/212) CRCs, respectively. The most frequent mutations in KRAS, BRAF and PIK3CA were G12D, V600E and H1047R, respectively. All BRAF and $80.8 \%$ PIK3CA mutations were from colon cancer patients. BRAF V600E was associated with advanced TNM $(P<0.001)$, more distant metastases $(P=0.025)$, and worse overall survival $(O S, P<0.001$; multivariate $H R=4.2$, $\mathrm{P}=0.004)$ in colon cancer patients. Compared with KRAS wt/BRAF wt CRC patients $(\mathrm{N}=109)$, those with KRAS codon 13 mutations $(N=25)$ had significantly worse $O S(P=0.016$; multivariate $H R=2.7, P=0.011)$, whereas KRAS codon 12-mutated cases were not significantly associated with survival. Among the three most common KRAS mutations, G13D ( $N=23)$ showed significant association with poor $O S(P=0.024$; multivariate $H R=2.6, P=0.016)$ compared with KRAS wt/BRAF wt patients.

Conclusion: Our findings indicate that PI3K/RAS-RAF signaling pathway genes are frequently mutated in Chinese CRC patients, but have different characteristics than found in Western patients. BRAF V600E is an independent prognostic factor for Chinese patients. Our finding that KRAS codon 13 mutations (in particular G13D) are associated with inferior survival in BRAF wild-type CRCs in Chinese patients was not reported thus far. Our data emphasizes the importance of prospective evaluation of molecular features in CRC patients, because a single mutation type may represent a distinct biologic effect and clinical implication.
\end{abstract}

Keywords: Colorectal cancer, BRAF, KRAS, Survival, Prognosis

\footnotetext{
* Correspondence: heyouji@seu.edu.cn

${ }^{1}$ Department of Pathogenic Biology and Immunology, Medical School of Southeast University, 87 Dingjiaoqiao, Nanjing 210009, Jiangsu, China

Full list of author information is available at the end of the article
} 


\section{Background}

Colorectal cancer (CRC) is one of the most common malignancies both in Western and in Asian countries [1]. In recent years, the morbidity and mortality of CRC have increased rapidly in the Chinese population, so that CRC has become the third leading cause of cancer deaths in China [2]. CRC arises through a multistep carcinogenic process with an accumulation of epigenetic and genetic alterations. Activation of two main EGFR-dependent signaling pathways, the RAS-RAF and the PI3K-PTENAKT pathways through mutations was considered to be one of the most common mechanisms involved in colorectal carcinogenesis. Numerous studies have indeed observed that KRAS, BRAF and PIK3CA mutations are commonly present in CRC, with frequencies of $30-50 \%$, $10-15 \%$ and $10-20 \%$, respectively. KRAS mutations occur $90 \%$ in exon 2 at codons 12 and 13. BRAF mutations are mostly located at codon 600 with a conversion of valine to glutamic acid (V600E) [3].

Although the predictive role of KRAS mutations, and more recently also $B R A F$ mutations to recognize resistance to anti-EGFR therapy in advanced CRC patients has been accepted widely [3-7], the prognostic role of KRAS mutations in CRCs for survival is still controversial [8-12]. For the BRAF V600E mutation, many studies have shown its association with a poor clinical outcome $[9,10,12,13]$. Given that mutations in KRAS and BRAF are mutually exclusive, $B R A F$ mutations may have potential confounding effect when estimating the prognostic value of KRAS mutations. It was recognized only recently in the studies of Yokota $(\mathrm{N}=229)$ [13] and Imamura $(\mathrm{N}=1261)$ [14] that the prognostic significance of KRAS mutation can be better examined in BRAF wild-type CRCs, because almost all $B R A F$ mutant patients are $K R A S$ wild-type.

Other studies have shown that different KRAS mutations in CRCs may have different biological characteristics and may consequently have variable effects in patients. Firstly, an in vitro study showed that KRAS codon $13 \mathrm{mu}-$ tations (mainly the p.G13D mutation) exhibited weaker transforming activity than codon 12 mutations [15]. Secondly, several clinical studies compared the prognostic roles of KRAS codon 12 mutations with those of codon 13 , but did not yet reach consensus because of the limited results, though most studies agreed that KRAS mutations in codon 13 confered a poorer prognosis and outcome for patients under standard chemotherapy [13,14,16-18]. Thirdly, a recent retrospective study of De Rook et al. analyzed the association between KRAS mutations in codon 13 (G13D) versus codon 12 evaluating response and survival in patients with chemotherapy refractory treated with cetuximab, and showed that patients with the KRAS G13D mutation could benefit from cetuximab therapy, whereas those with a KRAS codon 12 mutation were likely to be resistant to cetuximab [19]. An increasing number of sometimes contradictory studies showed that patients with KRAS mutations in codon 13 could have a poorer outcome, but would significantly benefit clinically from an anti-EGFR therapy [20]. Apparently, the real mechanism by which different KRAS mutations affect tumor biology and lead to different outcomes needs to be further elucidated.

PIK3CA mutations cluster 90\% in hotspots of exons 9 and 20 , and affect the functionally important helical and kinase domains. PIK3CA mutations are likely to be associated with a poor prognosis $[21,22]$ and clinical resistance to anti-EGFR targeted therapy [23].

Most of the studies that investigated the frequencies and prognostic values of KRAS, BRAF, PIK3CA mutations, and in particular, the efficacies of targeted therapies were performed in Western countries. There is not yet agreement on mutation frequencies in Chinese CRC patients, especially for $B R A F$ and PIK3CA, because the frequencies of such mutations were reported differently in the few data published (Table 1). Furthermore, little is known about their prognostic value in Chinese CRC patients, since few studies had follow-up data. In our study, we aimed to identify the mutation frequencies of $K R A S$, $B R A F$ and PIK3CA in primary tumors of a cohort of 214 Chinese CRC patients, and to assess their correlations with the clinicopathological characteristics. In addition, follow-up data were collected from all patients to determine their potential prognostic roles in survival.

\section{Methods}

\section{Patients and tumor samples}

Among the 436 consecutive patients diagnosed with colorectal cancer at Zhongda Hospital Affiliated to Southeast University (Nanjing, China) from 2007 to 2012, 35 were excluded because no surgery was performed. An additional 140 patients were excluded, as they were lost during follow-up period. Among the 261 patients eligible for the genetic testing, 38 patients were excluded because no tissue blocks were available. An extra 9 patients were excluded from the remaining 223 patients because of poor DNA quality. At last 214 patients were included in our study (Figure 1). There was no difference in the major clinicopathological characteristics between the included and excluded patients (see Additional file 1). All of these patients were histologically confirmed colorectal cancer by two experienced pathologists. None of the patients received any adjuvant therapy before resection. The median follow-up time of surviving patients was 34 months. The patients' demographic and clinicopathological data are presented in Table 2. The collection of materials and patient data was approved by the Institutional Ethics Committee of Zhongda Hospital and written informed consent was obtained from the participants. The study 
Table 1 Studies on mutation status of KRAS, BRAF and PIK3CA in Chinese CRC patients

\begin{tabular}{|c|c|c|c|c|c|}
\hline Reference (year) & $\begin{array}{c}\text { No. of } \\
\text { patients }\end{array}$ & Method & Mutation frequencies & Region & Prognostic value \\
\hline $\begin{array}{l}\text { [2] Gao J., et al. } \\
(2011)\end{array}$ & 273 & Direct sequencing & KRAS (38.5\%); BRAF (5.1\%) & Chinese & \\
\hline $\begin{array}{l}\text { [24] Li H.T., et al. } \\
\text { (2011) }\end{array}$ & 200 & Pyrosequencing & $\begin{array}{l}\text { KRAS }(31.5 \%) ; \operatorname{BRAF}(7.0 \%) ; \\
\text { PIK3CA (12.5\%) }\end{array}$ & Chinese & $\begin{array}{l}\text { KRAS and PIK3CA bi-mutations were more } \\
\text { likely to develop liver metastases. }\end{array}$ \\
\hline $\begin{array}{l}\text { [25] Shen H., et al. } \\
\text { (2011) }\end{array}$ & 118 & Pyrosequencing & $\operatorname{KRAS}(34.7 \%) ; \operatorname{BRAF}(1.7 \%)$ & Chinese & \\
\hline $\begin{array}{l}\text { [26] Liou J.M., et al. } \\
\text { (2011) }\end{array}$ & 314 & Direct sequencing & KRAS (20.7\%); BRAF (3.8\%) & Taiwan & $\begin{array}{c}\text { BRAF mutation was associated with worse } \\
\text { overall survival. }\end{array}$ \\
\hline $\begin{array}{l}\text { [27] Mao C., et al. } \\
\text { (2012) }\end{array}$ & 69 & Direct sequencing & $\begin{array}{c}\text { KRAS (43.9\%); BRAF (25.4\%); } \\
\text { PIK3CA (8.2\%) }\end{array}$ & Chinese & \\
\hline $\begin{array}{l}\text { [28] Hsieh L.L., et al. } \\
\text { (2012) }\end{array}$ & 182 & $\begin{array}{l}\text { Direct sequencing \& } \\
\text { HRM }\end{array}$ & $\begin{array}{c}\text { KRAS (33.5\%); BRAF (1.1\%); } \\
\text { PIK3CA (7.1\%) }\end{array}$ & Taiwan & \\
\hline $\begin{array}{l}\text { [29] Zhu Y.F., et al. } \\
\text { (2012) }\end{array}$ & 60 & Direct sequencing & PIK3CA (21.6\%) & Chinese & $\begin{array}{c}\text { High PI3K expression was associated } \\
\text { with CRC metastases. }\end{array}$ \\
\hline $\begin{array}{l}\text { [30] Li Z., et al. } \\
\text { (2012) }\end{array}$ & 78 & Direct sequencing & KRAS (33.3\%) & Chinese & $\begin{array}{c}\text { KRAS mutations were associated with poor } \\
\text { survival and liver metastasis. }\end{array}$ \\
\hline $\begin{array}{l}\text { [31] Shen Y., et al. } \\
\qquad(2013)\end{array}$ & 676 & Direct sequencing & $\begin{array}{c}\text { KRAS (35.9\%); BRAF (6.96\%); } \\
\text { PIK3CA (9.9\%) }\end{array}$ & Chinese & \\
\hline [32] Pu X., et al. (2013) & 115 & Direct sequencing & KRAS (32.2\%); BRAF (3.5\%) & Chinese & \\
\hline $\begin{array}{l}\text { [33] Wang J., et al. } \\
\text { (2013) }\end{array}$ & 574 & Direct sequencing & KRAS (34.2\%) & Chinese & \\
\hline $\begin{array}{l}\text { [34] Chang Y.S., et al. } \\
\text { (2013) }\end{array}$ & 165 & HRM & KRAS (36.97\%); BRAF (4.24\%) & Taiwan & $\begin{array}{c}\text { KRAS mutation was associated with } \\
\text { poor survival. }\end{array}$ \\
\hline
\end{tabular}

was conducted according to the institutional Guidelines and the regulations set by Chinese law for the use of human material for research.

\section{DNA extraction and mutation analysis}

Genomic DNA was extracted from 5 sections of $10 \mu \mathrm{m}$ thickness of macro-dissected formalin-fixed paraffinembedded (FFPE) tumor samples, containing at least 50\% tumor epithelium, as determined by an experienced

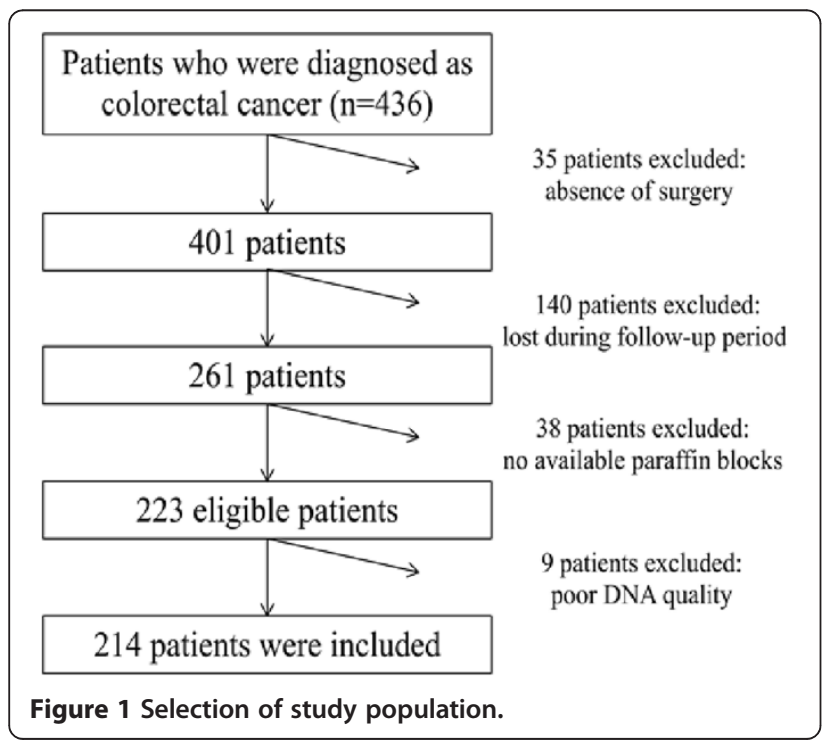

pathologist in H\&E-stained paraffin sections. The QIAmp DNA Mini Kits (Qiagen GmbH, Hilden, Germany) was used according to the manufacturer's instructions. For each sample, exons 9 and 20 of PIK3CA, exon 2 of KRAS, and exon 15 of $B R A F$ were amplified by PCR. The presence of mutations was detected by direct sequencing at Beijing Genomic Institute (BGI, ABI 3730xL Genetic analyzer, Shenzhen, China) using the BigDye Terminator Cycle Sequencing kit (Applied Biosystems). For all PCR products with sequence variants, both forward and reverse sequence reactions were repeated for confirmation. Primers used for the amplification are listed in Table 3.

\section{Statistical analysis}

All statistical analyses were carried out with SPSS statistical software (version 18.0 for Windows, SPSS, Inc.). Data were analyzed with the Mann-Whitney test to compare quantitative and ordered variables and with Student's t test to compare normally distributed data between two groups. $\chi^{2}$ test and Fisher's exact test were used to compare proportions. Survival analyses were done using the Kaplan-Meier (KM) method with time of surgery as entry date. Overall survival (OS) was defined as the period from the date of surgery until death from any cause or last follow-up. Log rank testing was used for comparison of groups.

To identify factors associated with OS, we evaluated the following clinicopathological variables in a univariate Cox 
Table 2 Clinicopathological characteristics according to PI3K/RAS-RAF pathway gene mutation status in 214 (212) colorectal cancer patients

\begin{tabular}{|c|c|c|c|c|c|c|c|c|c|c|c|c|c|c|}
\hline & & \multirow[b]{2}{*}{ No. patients $(214 / 212)$} & \multicolumn{3}{|c|}{ KRAS exon 2} & \multicolumn{3}{|c|}{ BRAF exon 15} & \multicolumn{3}{|c|}{ PIK3CA exon 9\&20* } & \multicolumn{3}{|c|}{ PI3K/RAS-RAF pathway* } \\
\hline & & & No (\%) & Yes (\%) & $\mathbf{P}$ & No (\%) & Yes (\%) & $\mathbf{P}$ & No (\%) & Yes (\%) & $\mathbf{P}$ & No (\%) & Yes (\%) & $\mathbf{P}$ \\
\hline \multirow[t]{2}{*}{ Sex } & male & $127(126)$ & $73(61.9)$ & $54(56.3)$ & $0.406^{\mathrm{a}}$ & $122(59.5)$ & $5(55.6)$ & $1.000^{b}$ & $109(58.6)$ & $17(65.4)$ & $0.509^{\mathrm{a}}$ & $60(61.2)$ & $66(57.9)$ & $0.623^{\mathrm{a}}$ \\
\hline & female & $87(86)$ & $45(38.1)$ & $42(43.8)$ & & $83(40.5)$ & $4(44.4)$ & & $77(41.4)$ & $9(34.6)$ & & $38(38.8)$ & $48(42.1)$ & \\
\hline Age & & 68.0 & 67.1 & 69.1 & $0.286^{d}$ & 68.0 & 66.9 & $0.801^{d}$ & 68.7 & 64.6 & $0.133^{d}$ & 67.8 & 68.4 & $0.728^{d}$ \\
\hline \multirow[t]{2}{*}{ Location } & colon & $126(124)$ & $73(61.9)$ & $53(55.2)$ & $0.325^{a}$ & $117(57.1)$ & $9(100.0)$ & $0.011^{b}$ & $103(55.4)$ & $21(80.8)$ & $0.014^{\mathrm{a}}$ & $54(55.1)$ & $70(61.4)$ & $0.353^{\mathrm{a}}$ \\
\hline & rectum & $88(88)$ & $45(38.1)$ & $43(44.8)$ & & $88(42.9)$ & $0(0)$ & & $83(44.6)$ & $5(19.2)$ & & $44(44.9)$ & $44(38.6)$ & \\
\hline \multirow[t]{4}{*}{ Differentiation } & well & $29(29)$ & $19(16.1)$ & $10(10.4)$ & $0.912^{c}$ & $28(13.7)$ & $1(11.1)$ & $0.131^{c}$ & $22(11.8)$ & $7(26.9)$ & $0.215^{c}$ & $15(15.3)$ & $14(12.3)$ & $0.521^{c}$ \\
\hline & moderate & $163(161)$ & $83(70.3)$ & $80(83.3)$ & & 159 (77.6) & $4(44.4)$ & & $145(78.0)$ & $16(61.5)$ & & $73(74.5)$ & $88(77.2)$ & \\
\hline & poor & $7(7)$ & $7(5.9)$ & $0(0)$ & & $5(2.4)$ & $2(22.2)$ & & $5(2.7)$ & $2(7.7)$ & & $3(3.1)$ & $4(3.5)$ & \\
\hline & missing & $15(15)$ & $9(7.6)$ & $6(6.3)$ & & $13(6.3)$ & $2(22.2)$ & & $14(7.5)$ & $1(3.8)$ & & $7(7.1)$ & $8(7.0)$ & \\
\hline \multirow[t]{3}{*}{ Tumor diameter } & $<5 \mathrm{~cm}$ & $103(102)$ & $53(44.9)$ & $50(52.1)$ & $0.254^{c}$ & $101(49.3)$ & $2(22.2)$ & $0.171^{b}$ & $93(50.0)$ & $9(34.6)$ & $0.172^{\mathrm{a}}$ & $46(46.9)$ & $56(49.1)$ & $0.710^{\mathrm{a}}$ \\
\hline & $>=5 \mathrm{~cm}$ & $108(107)$ & $64(54.2)$ & $44(45.8)$ & & $101(49.3)$ & $7(77.8)$ & & $91(48.9)$ & $16(61.5)$ & & $51(52.0)$ & $56(49.150 .0)$ & \\
\hline & missing & 3 (3) & $1(0.8)$ & $2(2.1)$ & & $3(1.5)$ & $0(0)$ & & $2(1.1)$ & $1(3.8)$ & & $1(1.0)$ & $2(1.8)$ & \\
\hline \multirow[t]{5}{*}{ TNM-stage } & । & $32(32)$ & $15(12.7)$ & $17(17.7)$ & $0.828^{c}$ & $32(15.6)$ & $0(0)$ & $0.007^{c}$ & $26(14.0)$ & $6(23.1)$ & $0.433^{c}$ & $13(13.3)$ & $19(16.7)$ & $0.231^{c}$ \\
\hline & $\|$ & $78(77)$ & $50(42.4)$ & $28(29.2)$ & & 76 (37.1) & $2(22.2)$ & & $69(37.1)$ & $8(30.8)$ & & $44(44.9)$ & $33(28.9)$ & \\
\hline & III & $82(81)$ & $38(32.2)$ & $44(45.8)$ & & 79 (38.5) & $3(33.3)$ & & $70(37.6)$ & $11(42.3)$ & & $31(31.6)$ & $50(43.9)$ & \\
\hline & IV & $19(19)$ & $13(11.0)$ & $6(6.3)$ & & $15(7.3)$ & $4(44,4)$ & & $18(9.7)$ & $1(3.8)$ & & $8(8.2)$ & $11(9.6)$ & \\
\hline & missing & 3 (3) & $2(1.7)$ & $1(1.0)$ & & $3(1.5)$ & $0(0)$ & & $3(1.6)$ & $0(0)$ & & $2(2.0)$ & $1(0.9)$ & \\
\hline \multirow[t]{5}{*}{$\mathrm{T}$} & $\mathrm{T} 1$ & $5(5)$ & $4(3.4)$ & $1(1.0)$ & $0.236^{c}$ & $5(2.4)$ & $0(0)$ & $0.057^{c}$ & $5(2.7)$ & $0(0)$ & $0.808^{c}$ & $4(4.1)$ & $1(0.9)$ & $0.724^{c}$ \\
\hline & $\mathrm{T} 2$ & 35 (35) & 15 (12.7) & $20(20.8)$ & & 35 (17.1) & $0(0)$ & & $29(15.6)$ & $6(23.1)$ & & $13(13.3)$ & $22(19.3)$ & \\
\hline & T3 & $167(166)$ & 93 (78.8) & 74 (77.1) & & 159 (77.6) & $8(88.9)$ & & $147(79.0)$ & $19(73.1)$ & & 77 (78.6) & 89 (78.1) & \\
\hline & T4 & $5(4)$ & $4(3.4)$ & $1(1.0)$ & & $4(2.0)$ & $1(11.1)$ & & $3(1.6)$ & $1(3.8)$ & & $2(2.0)$ & $2(1.8)$ & \\
\hline & missing & $2(2)$ & $2(1.7)$ & $0(0)$ & & $2(1.0)$ & $0(0)$ & & $2(1.1)$ & $0(0)$ & & $2(2.0)$ & $0(0)$ & \\
\hline \multirow[t]{3}{*}{$N$} & $N(-)$ & 115 (114) & $70(59.3)$ & $45(46.9)$ & $0.050^{\mathrm{a}}$ & $113(55.1)$ & $2(22.2)$ & $0.083^{b}$ & $99(53.2)$ & $15(57.7)$ & $0.710^{a}$ & $61(62.2)$ & $53(46.5)$ & $0.013^{a}$ \\
\hline & $N(+)$ & $97(96)$ & 46 (39.0) & $51(53.1)$ & & 90 (43.9) & $7(77.8)$ & & $85(45.7)$ & $11(42.3)$ & & $35(35.7)$ & $61(53.5)$ & \\
\hline & missing & $2(2)$ & $2(1.7)$ & $0(0)$ & & $2(1.0)$ & $0(0)$ & & $2(1.1)$ & $0(0)$ & & $2(2.0)$ & $0(0)$ & \\
\hline \multirow[t]{2}{*}{ Metastases } & $M(-)$ & $163(161)$ & $88(74.6)$ & $75(78.1)$ & $0.367^{\mathrm{a}}$ & $159(77.6)$ & $4(44.4)$ & $0.037^{b}$ & $144(77.4)$ & $17(65.4)$ & $1.808^{\mathrm{a}}$ & 77 (78.6) & $84(73.7)$ & $0.689^{a}$ \\
\hline & $M(+)$ & $51(51)$ & $30(25.4)$ & 21 (21.9) & & 46 (22.4) & $5(55.6)$ & & $42(22.6)$ & $9(34.6)$ & & $21(21.4)$ & $30(26.3)$ & \\
\hline \multirow[t]{3}{*}{ Synchronous metastases } & $M(-)$ & $193(191)$ & $104(88.1)$ & $89(92.7)$ & $0.224^{a}$ & $188(91.7)$ & $5(55.6)$ & $0.004^{b}$ & $166(89.2)$ & $25(96.2)$ & $0.479^{b}$ & $89(90.8)$ & $102(89.5)$ & $0.708^{\mathrm{a}}$ \\
\hline & $M(+)$ & $19(19)$ & $13(11.0)$ & $6(6.3)$ & & $15(7.3)$ & $4(44.4)$ & & $18(9.7)$ & $1(3.8)$ & & $8(8.2)$ & $11(9.6)$ & \\
\hline & missing & $2(2)$ & $1(0.8)$ & $1(1.0)$ & & $2(1.0)$ & $0(0)$ & & $2(1.1)$ & $0(0)$ & & $1(1.0)$ & $1(1.0)$ & \\
\hline \multirow[t]{2}{*}{ Metachronous metastases } & $M(-)$ & $176(174)$ & $95(80.5)$ & $81(84.4)$ & $0.462^{\mathrm{a}}$ & $171(83.4)$ & $5(55.6)$ & $0.055^{b}$ & $156(83.9)$ & $18(69.2)$ & $0.097^{b}$ & $82(83.7)$ & $92(80.7)$ & $0.574^{\mathrm{a}}$ \\
\hline & $M(+)$ & $38(38)$ & $23(19.5)$ & $15(15.6)$ & & $34(16.6)$ & $4(44.4)$ & & $30(16.1)$ & $8(30.8)$ & & $16(16.3)$ & $22(19.3)$ & \\
\hline
\end{tabular}


Table 3 The primers used in PCR amplification and sequencing

\begin{tabular}{ll}
\hline Genes & \multicolumn{1}{c}{ Primers (sequence $\mathbf{5}^{\prime}-\mathbf{>} \mathbf{3}^{\prime}$ ) } \\
\hline KRAS & F: TTAACCTTATGTGTGACATGTTCTAA \\
R: ATCAAAGAATGGTCCTGCAC & \\
BRAF & F: CTTACTAACTACACCTCAG \\
Exon $\mathbf{1 5}$ & R: TAACTCAGCAGCATCTCAGG \\
PIK3CA & F: AGTAACAGACTAGCTAGAGACAAT \\
Exon $\mathbf{9}$ & R: CATGCTGAGATCAGCCAAAT \\
Exon $\mathbf{2 0}$ & F: ATGATGCTTGGCTCTGGAAT \\
& R: TGTGGAATCCAGAGTGAGCTT \\
\hline
\end{tabular}

regression model: age ( $>65 v s \leq 65)$, sex (male $v s$ female), tumor location (colon $v s$ rectum), tumor differentiation grade, tumor diameter $(<5 \mathrm{~cm} v s \geq 5 \mathrm{~cm})$, number of lymph nodes examined ( $<12 v s \geq 12)$, TNM stage, KRAS status (mutant $v s$ wild-type (wt)), BRAF status (mutant $v s \mathrm{wt}$ ) and PIK3CA status (mutant vs wt). All variables associated with OS with $P<0.1$ in the univariate analysis were entered into a Cox multivariate regression model with backward elimination. A two-sided $\mathrm{P}$ value of $\leq 0.05$ was considered statistically significant.

\section{Results}

\section{Frequency and distribution of KRAS, BRAF and PIK3CA mutations}

KRAS mutation status in exon 2 was detected in 96 out of 214 (44.9\%) tumor samples, of which 70 (32.7\%) had a single mutation and one had two mutations in codon 12 , and $25(11.7 \%)$ had a single mutation in codon 13. The most frequent mutation was 35G > A (G12D), which represented $35.4 \%$ of all KRAS mutations, followed by 38G > A (G13D, 24.0\%). BRAF mutations in exon 15 were found in 9 out of 214 (4.2\%) tumor samples. Only one case was 1801A > G (K601E), whereas the rest were $1799 \mathrm{~T}>\mathrm{A}$ (V600E) mutations. PIK3CA mutations were found in 26 out of 212 patients (12.3\%), with 12 cases in exon $9(5.7 \%)$ and 14 cases in exon 20 (6.6\%). The most frequently detected mutations were 1633G $>$ A (E545K) in exon 9 and 3140A > G (H1047R) in exon 20 among a total of 11 variants. Mutations are summarized in Table 4. The distribution of the mutations in 212 samples is shown in Figure 2. In total, 114 cases (53.8\%) had a mutation in at least one of the three genes, with $97 \mathrm{pa}$ tients (45.8\%) having a mutation in a single gene and 17 patients $(8.0 \%)$ in two genes. 16 cases had concomitant occurrence of KRAS and PIK3CA mutations, but this association was not statistically significant $(\mathrm{P}=0.075)$. Only one patient had a BRAF and a PIK3CA mutation
Table 4 KRAS, BRAF and PIK3CA mutations identified in 214 colorectal cancer patients

\begin{tabular}{|c|c|c|c|c|c|}
\hline & & Nucleotide & Amino acid & Case (total) & $\%$ \\
\hline \multirow[t]{10}{*}{ KRAS } & & & & $96(214)$ & 44.9 \\
\hline & exon 2 & $34 \mathrm{G}>\mathrm{A}$ & G12S & 2 & \\
\hline & & $34 G>C$ & G12R & 1 & \\
\hline & & $34 \mathrm{G}>\mathrm{T}$ & $\mathrm{G} 12 \mathrm{C}$ & 5 & \\
\hline & & $35 G>A$ & G12D & 34 & \\
\hline & & $35 G>C$ & G12A & 8 & \\
\hline & & $35 G>T$ & G12V & 20 & \\
\hline & & $35 G>T \& 35 G>A$ & G12V \& G12D & 1 & \\
\hline & & $37 G>T$ & G13C & 2 & \\
\hline & & $38 \mathrm{G}>\mathrm{A}$ & G13D & 23 & \\
\hline \multirow[t]{3}{*}{ BRAF } & & & & $9(214)$ & 4.2 \\
\hline & exon 15 & $1799 \mathrm{~T}>\mathrm{A}$ & V600E & 8 & \\
\hline & & $1801 A>G$ & K601E & 1 & \\
\hline \multirow[t]{14}{*}{ PIK3CA } & & & & $26(212)^{*}$ & 12.3 \\
\hline & exon 9 & & & 12 & 5.7 \\
\hline & & $1624 G>A$ & E542K & 1 & \\
\hline & & $1633 G>A$ & E545K & 7 & \\
\hline & & $1634 A>C$ & E545A & 1 & \\
\hline & & $1636 C>A$ & Q546K & 2 & \\
\hline & & $1637 A>G$ & Q546R & 1 & \\
\hline & exon 20 & & & 14 & 6.6 \\
\hline & & $3062 A>T$ & Y1021F & 2 & \\
\hline & & $3139 C>T$ & $\mathrm{H} 1047 \mathrm{Y}$ & 1 & \\
\hline & & $3140 A>G$ & H1047R & 8 & \\
\hline & & $3140 \mathrm{~A}>\mathrm{T}$ & H1047L & 1 & \\
\hline & & $3145 G>C$ & G1049R & 1 & \\
\hline & & $3155 C>A$ & T1052K & 1 & \\
\hline
\end{tabular}

*DNA of 2 samples was not available for PIK3CA exon 20 .

simultaneously. Mutations in $K R A S$ and $B R A F$ were not observed in the same tumor $(\mathrm{P}=0.005)$, which is consistent with previous studies stating that they were mutually exclusive [35].

\section{PI3K/RAS-RAF pathway mutations and clinicopathological} characteristics

We did not find any significant associations between KRAS mutations and patients' clinicopathological characteristics, except that KRAS mutations were associated with more lymph node involvement $(53.1 \%$ vs $46.9 \%$, $\mathrm{P}=0.050$ ). Data are shown in Table 2. Mutations in BRAF or PIK3CA showed a significant correlation with tumor location. All mutations in $B R A F$ were from colon cancer patients and almost all were localized in the proximal colon (8/9). Likewise, most mutations in PIK3CA were from colon cancer patients $(21 / 26, \mathrm{P}=0.014)$. Compared 


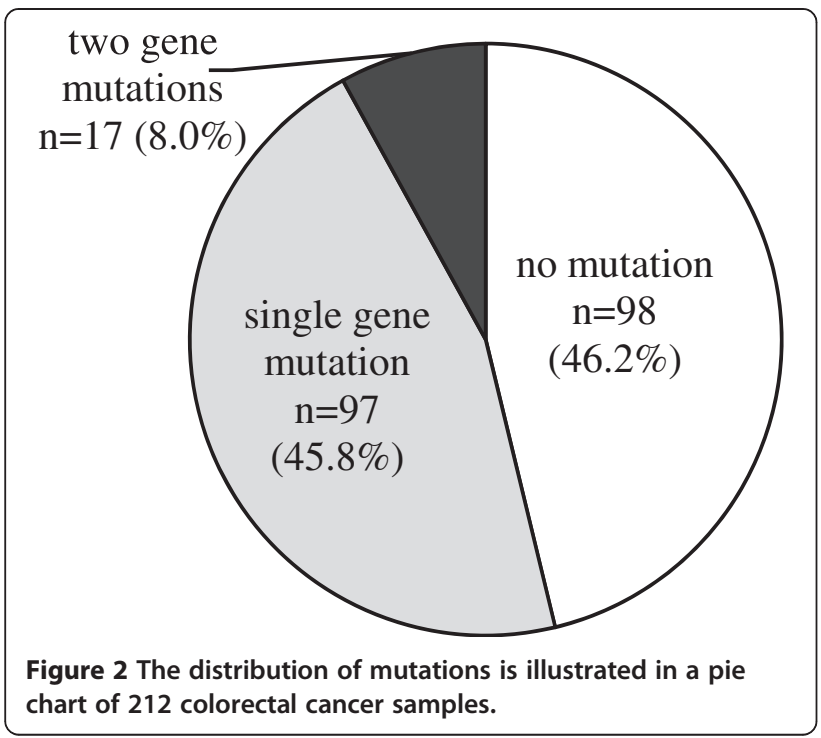

to patients without mutation (wild-type patients), those who harbored at least one mutation in any of the three genes were not different in any of the listed features except lymph-node involvement when admitted (53.5\% vs $35.7 \%, \mathrm{P}=0.013)$. There was no significant difference in listed features between those carrying two gene mutations and the wild-type patients (data not shown).

We further analyzed the impact of $B R A F$ mutation in the 126 colon-cancer patients. Among the 9 patients with a BRAF mutation, 8 were $\mathrm{V} 600 \mathrm{E}$ and 1 was K601E. As mutation in codon 601 does not have a clear biological function, we only took the V600E mutation into further analysis (Table 5). The V600E mutation was correlated with significantly higher TNM stage $(\mathrm{P}=0.014)$. Furthermore, patients with this BRAF mutation had a $>2.5$-fold higher risk for distant metastases than patients without this mutation $(62.5 \%$ vs $22.9 \%, \mathrm{P}=0.025)$. The risk for synchronous metastases was $>8$-fold higher in patients with than without this BRAF mutation $(50.0 \%$ vs $5.9 \%$, $\mathrm{P}=0.002$ ). Notably, 3 out of 8 patients with the V600E mutation developed both synchronous and metachronous metastases.

\section{Prognostic value of $B R A F$ and KARS codon 13 mutations} In a KM analysis of the BRAF V600E mutation in 126 colon patients, V600E was strongly associated with a poorer OS (log-rank $\mathrm{P}<0.001$; 3-year OS: $16.7 \%$ in the $B R A F$ V600E mutant $v s 73.2 \%$ in the BRAF wild-type (wt); Figure $3 \mathrm{~A}$ ). No differences were found between patients with and without $K R A S$ mutations (log-rank $\mathrm{P}=0.133$; 3 -year OS: $64.6 \%$ in the KRAS mutant vs $72.4 \%$ in the KRAS wt; Figure 3B) in the survival analysis. Similarly, no differences were found for PIK3CA mutations or at least one mutation in any of the three genes (data not shown). However, several recent studies suggested to exclude the
Table 5 Clinicopathological characteristics according to BRAF V600E mutation status in 126 colon cancer patients

\begin{tabular}{|c|c|c|c|c|}
\hline & & \multicolumn{3}{|c|}{ BRAF codon 600 mutation } \\
\hline & & No (\%) & Yes (\%) & $\mathbf{P}$ \\
\hline \multirow[t]{2}{*}{ Sex } & male & $71(60.2)$ & $5(62.5)$ & $1.000^{b}$ \\
\hline & female & $47(39.8)$ & $3(37.5)$ & \\
\hline Age & & 69.4 & 65.4 & $0.664^{d}$ \\
\hline \multirow[t]{4}{*}{ Differentiation } & well & $15(12.7)$ & $1(12.5)$ & $0.192^{c}$ \\
\hline & moderate & $91(77.1)$ & $3(37.5)$ & \\
\hline & poor & $5(4.2)$ & $2(25.0)$ & \\
\hline & missing & $7(5.9)$ & $2(25.0)$ & \\
\hline \multirow[t]{3}{*}{ Tumor diameter } & $<5 \mathrm{~cm}$ & $49(41.5)$ & $2(25.0)$ & $0.469^{b}$ \\
\hline & $>=5 \mathrm{~cm}$ & $67(56.8)$ & $6(75.0)$ & \\
\hline & missing & $2(1.7)$ & $0(0)$ & \\
\hline \multirow[t]{5}{*}{ TNM-stage } & । & $9(7.6)$ & $0(0)$ & $0.014^{c}$ \\
\hline & $\|$ & $50(42.4)$ & $2(25.0)$ & \\
\hline & III & $49(42.4)$ & $2(25.0)$ & \\
\hline & IV & $7(5.9)$ & $4(50.0)$ & \\
\hline & missing & $2(1.7)$ & $0(0)$ & \\
\hline \multirow[t]{5}{*}{$\mathbf{T}$} & $\mathrm{T} 1$ & $0(0)$ & $0(0)$ & $0.106^{c}$ \\
\hline & $\mathrm{T} 2$ & $9(7.6)$ & $0(0)$ & \\
\hline & T3 & $105(89.0)$ & 7 (87.5) & \\
\hline & T4 & $2(1.7)$ & $1(12.5)$ & \\
\hline & missing & $2(1.7)$ & $0(0)$ & \\
\hline \multirow[t]{3}{*}{$\mathrm{N}$} & $N(-)$ & $62(52.5)$ & $2(25.0)$ & $0.157^{\mathrm{b}}$ \\
\hline & $N(+)$ & $55(46.6)$ & $6(75.0)$ & \\
\hline & missing & $1(0.8)$ & $0(0)$ & \\
\hline \multirow[t]{2}{*}{ Metastases } & $M(-)$ & $91(77.1)$ & $3(37.5)$ & $0.025^{\mathrm{b}}$ \\
\hline & $M(+)$ & $27(22.9)$ & $5(62.5)$ & \\
\hline \multirow[t]{3}{*}{ Synchronous metastases } & $M(-)$ & $110(93.2)$ & $4(50.0)$ & $0.002^{\mathrm{b}}$ \\
\hline & $M(+)$ & $7(5.9)$ & $4(50.0)$ & \\
\hline & missing & $1(0.8)$ & $0(0)$ & \\
\hline \multirow[t]{2}{*}{ Metachronous metastases } & $M(-)$ & $96(81.4)$ & $4(50.0)$ & $0.056^{\mathrm{b}}$ \\
\hline & $M(+)$ & $22(18.6)$ & $4(50.0)$ & \\
\hline
\end{tabular}

${ }^{\mathrm{b}}$ Fisher exact test; ${ }^{\mathrm{C}}$ Mann-Whitney test; ${ }^{\mathrm{d}} \mathrm{t}$ test. P-values $\leq 0.05$ are in bold.

confounding effect of BRAF mutation from KRAS wt patients when evaluating the prognostic value of $K R A S$, as $B R A F$ mutation is associated with a poorer prognosis $[9,13,14]$. We then selected $B R A F$ wt cases only and compared KRAS-mutants/BRAF wt cases with KRAS wt/BRAF wt cases to assess the prognostic value of KRAS mutations. A total of 205 cases (214 cases - 9 BRAF mutants) remained in the analysis (Figure 4) with 52 death events. Intriguingly, KRAS mutations showed its prognostic value when $B R A F$ mutations were excluded in the $\mathrm{KM}$ analysis (log-rank $\mathrm{P}=0.035$; 3-year OS: $64.6 \%$ in KRAS mutants/ $B R A F$ wt vs $76.3 \%$ in $K R A S$ wt/BRAF wt; Figure 3C). We 

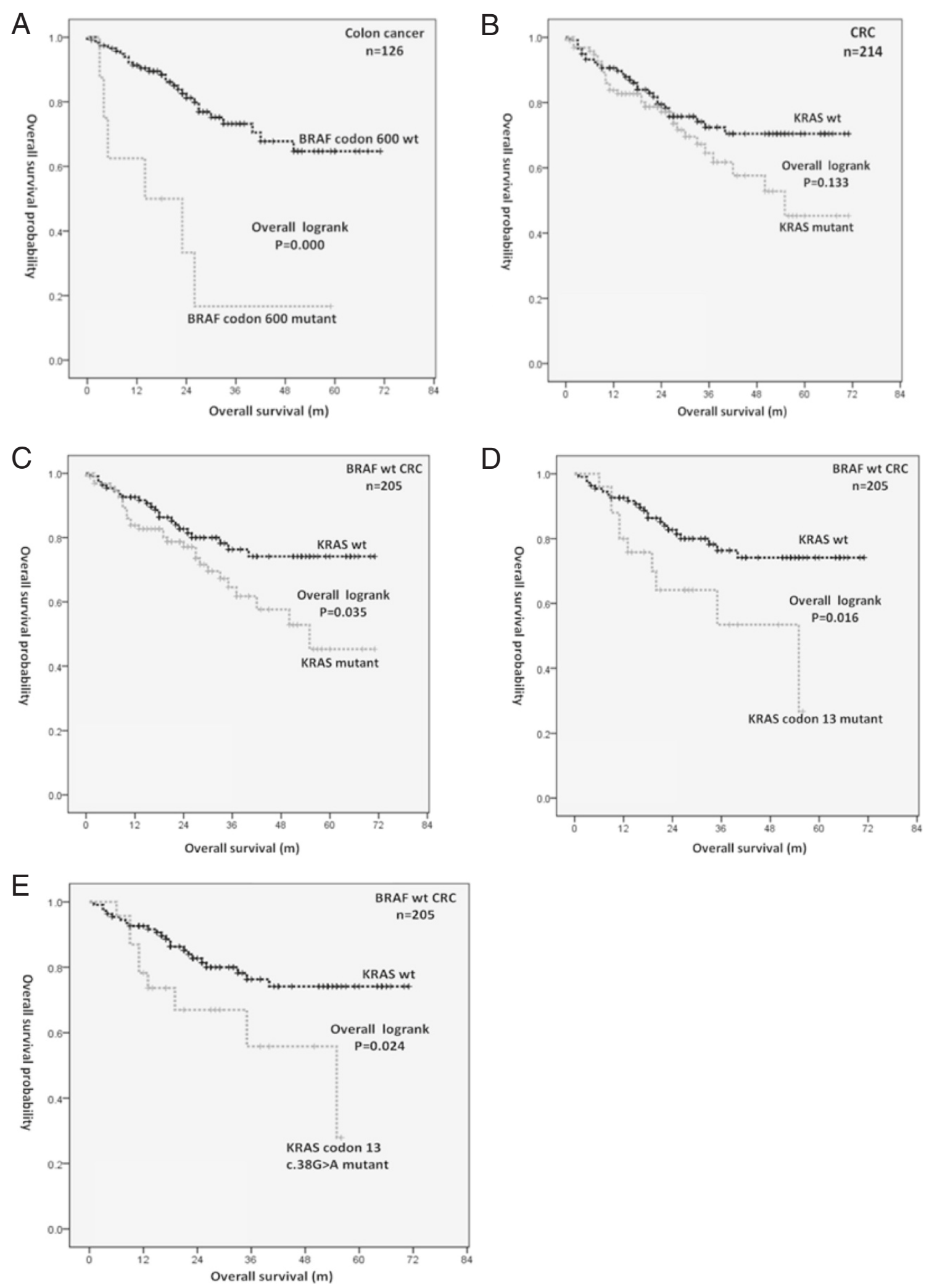

Figure 3 Kaplan-Meier curves. Panel A shows OS according to BRAF V600E mutation status in 126 colon cancer patients. Panel B shows OS according to KRAS mutation status in 214 colorectal cancer patients. Panels $\mathbf{C}, \mathbf{D}$ and $\mathbf{E}$ show OS according to KRAS, KRAS codon 13 and KRAS c.38G > A (G13D) mutation status in 205 BRAF wild-type colorectal cancer patients, respectively. 


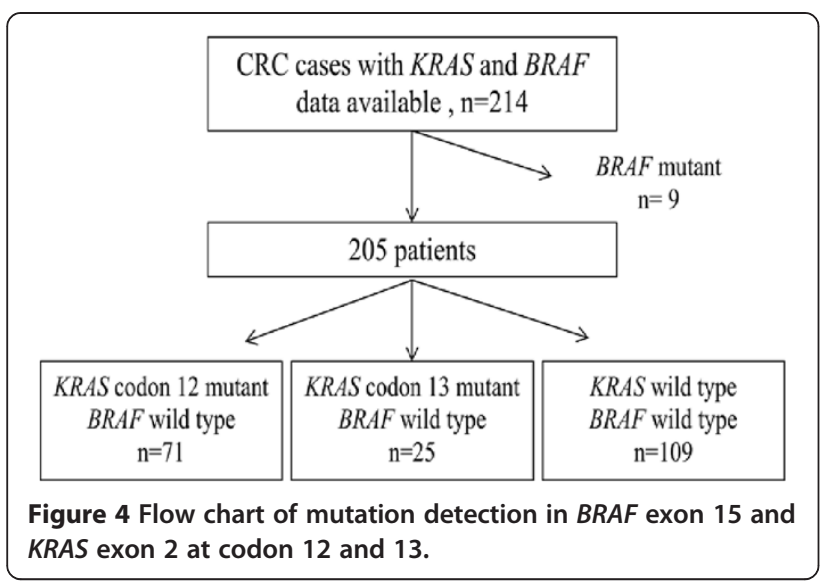

further analyzed the prognostic roles of two subtypes of KRAS mutations. Interestingly, patients with a KRAS codon 13 mutation experienced a significant decrease in OS in KM analysis compared with patients with a KRAS wt $/ B R A F$ wt genotype (log-rank $\mathrm{P}=0.016$; 3-year OS: $53.4 \%$ in KRAS codon 13 mutants/BRAF wt vs $76.3 \%$ in $K R A S \mathrm{wt} / B R A F \mathrm{wt}$; Figure 3D), while KRAS codon $12 \mathrm{mu}-$ tations did not show this effect. Among the 3 most common KRAS codon 12 and 13 mutations analyzed, c.38G > A (p.G13D; $\mathrm{N}=23$ ) was significantly associated with worse OS compared with KRAS wt/BRAF wt (log-rank $\mathrm{P}=0.024$; 3-year OS: $55.8 \%$ in KRAS c.38G > A mutants/ $B R A F$ wt vs $76.3 \%$ in KRAS wt/BRAF wt; Figure 3E).

\section{Univariate and multivariate analysis of outcome predictors}

To correct for significant prognostic factors, variables including age, sex, differentiation grade, tumor diameter, number of lymph nodes examined, TNM stage and KRAS/BRAF/PIK3CA genotype were first examined in colon cancer patients with the univariate Cox regression model (Table 6). Besides sex $(P=0.009)$ and TNM stage ( $\mathrm{P} \leq 0.000)$, BRAF V600E mutation showed a significant association with a higher risk of overall mortality (hazard ratio (HR), 5.1; 95\% confidence interval $(\mathrm{CI}), 2.1-12.4 ; \mathrm{P} \leq 0.001)$. The independent prognostic value of the BRAF V600E mutation was further tested in multivariate analysis with backward stepwise elimination, including the following variables: sex, TNM stage and BRAF V600E mutation. No significant interactions were observed between the variables. The $B R A F$ V600E mutation remained as an independent predictor for poor prognosis in patients with colon cancer (HR, 4.2; 95\% CI, 1.6-11.0; P = 0.004) (Table 6). Compared with the KRAS wt/BRAF wt cases, those with a $K R A S$ codon 13 mutation experienced a significant decrease in OS in the Cox regression analysis (univariate: $\mathrm{HR}, 2.5,95 \% \mathrm{CI}, 1.2-5.2 ; \mathrm{P}=0.019$; multivariate: $\mathrm{HR}, 2.7$, 95\% CI, 1.3-5.7; $\mathrm{P}=0.011$; Table 7). In contrast, patients
Table 6 Analysis of OS in 126 colon cancer patients by Cox regression analysis

\begin{tabular}{|c|c|c|c|c|}
\hline \multirow[t]{2}{*}{ Variables } & \multicolumn{2}{|c|}{ Univariate analysis } & \multicolumn{2}{|c|}{ Multivariate analysis } \\
\hline & HR $(95 \% \mathrm{Cl})$ & $\mathbf{P}$ & HR $(95 \% \mathrm{Cl})$ & $\mathbf{P}$ \\
\hline Age & & 0.995 & & \\
\hline$<=65$ & 1.0 & & & \\
\hline$>65$ & $1.0(0.5-2.108)$ & & & \\
\hline Sex & & 0.009 & & 0.009 \\
\hline Female & 1.0 & & 1.0 & \\
\hline Male & $3.0(1.3-7.0)$ & & $3.3(1.3-7.8)$ & \\
\hline Differentiation & & 0.160 & & \\
\hline well & 1.0 & & & \\
\hline moderate & $0.5(0.2-1.1)$ & 0.089 & & \\
\hline poor & $1.0(0.3-3.9)$ & 0.962 & & \\
\hline Lymphnode examined & & 0.052 & & \\
\hline$>12$ & 1.0 & & & \\
\hline$<=12$ & $2.0(1.0-4.1)$ & & & \\
\hline Tumor diameter & & 0.188 & & \\
\hline$<5 \mathrm{~cm}$ & 1.0 & & & \\
\hline$>=5 \mathrm{~cm}$ & $1.7(0.8-3.5)$ & & & \\
\hline TNM-stage & & $<0.001$ & & 0.017 \\
\hline । & 1.0 & & 1.0 & \\
\hline$\|$ & $1.4(0.2-10.8)$ & 0.749 & $1.3(0.2-9.9)$ & \\
\hline III & $1.8(0.2-13.9)$ & 0.568 & $2.1(0.3-15.9)$ & \\
\hline IV & $9.7(1.2-78.3)$ & 0.032 & $5.8(0.7-47.8)$ & \\
\hline KRAS status & & 0.795 & & \\
\hline wt & 1.0 & & & \\
\hline mutant & $1.1(0.5-2.2)$ & & & \\
\hline BRAF V600E status & & $<0.001$ & & 0.004 \\
\hline wt & 1.0 & & 1.0 & \\
\hline mutant & $5.1(2.1-12.4)$ & & $4.2(1.6-11.0)$ & \\
\hline PIK3CA status & & 0.727 & & \\
\hline$w t$ & 1.0 & & & \\
\hline mutant & $1.2(0.5-2.8)$ & & & \\
\hline
\end{tabular}

P-values $\leq 0.05$ are in bold.

with KRAS codon 12 mutations did not experience a significant decrease in survival. Among the 3 most common KRAS codon 12 and 13 mutations, c.38G > A (G13D, N =23) was associated with significantly lower OS compared with the KRAS wt/BRAF wt patients (univariate HR, 2.4, 95\% CI, 1.1-5.3; $\mathrm{P}=0.026$; multivariate $\mathrm{HR}, 2.6$, 95\% CI, 1.2-5.8; P = 0.016; Table 8).

\section{Discussion}

In this study, we determined mutation frequencies of KRAS, BRAF and PIK3CA in 214 Chinese CRC patients with resectable tumors and examined the correlations between their genotypes and clinicopathological 
Table 7 Analysis of OS according to KRAS mutation status in 205 BRAF wt colorectal cancer patients by cox regression analysis

\begin{tabular}{|c|c|c|c|c|c|c|c|}
\hline \multirow[b]{2}{*}{ KRAS } & \multirow[b]{2}{*}{$B R A F$} & \multirow[b]{2}{*}{ Total $\mathbf{N}$} & \multirow[b]{2}{*}{ No. of events } & \multicolumn{2}{|c|}{ Univariate analysis } & \multicolumn{2}{|c|}{ Multivariate analysis } \\
\hline & & & & HR $(95 \% \mathrm{Cl})$ & $\mathbf{P}$ & HR (95\% Cl) & $\mathbf{P}$ \\
\hline wt & wt & 109 & 22 & 1.0 & & 1.0 & \\
\hline All codon 12 mutants & wt & 71 & 20 & $1.6(0.9-2.9)$ & 0.139 & $1.4(0.8-2.6)$ & 0.247 \\
\hline All codon 13 mutants & wt & 25 & 10 & $2.5(1.2-5.2)$ & 0.019 & $2.7(1.3-5.7)$ & 0.011 \\
\hline
\end{tabular}

NOTE: We tested KRAS codon 12 and 13 mutations among BRAF wild type cases.

The multivariate Cox regression model initially included age, sex, tumor location, tumor differentiation, tumor diameter, number of lymph nodes examined, TNM stage, KRAS and PIK3CA status. A backward stepwise elimination with a threshold of $\mathrm{P}=0.1$ was used to select variables in the final model. TNM stage and KRAS status were finally entered the multivariate analysis. P-values $\leq 0.05$ are in bold.

characteristics. Our data showed that BRAF and PIK3CA mutations were related to tumor site. In addition, we clarified the prognostic values of $B R A F$ V600E mutation and KRAS mutations in codon 13. To the best of our knowledge, we assessed for the first time the impact of KRAS mutations, including distinguished mutation subtypes, on prognosis in Chinese CRC patients when the confounding effect of a $B R A F$ mutation was controlled.

Comparing our results with the studies from Western countries, differences in mutation distribution and frequency were observed. We identified a frequency of $~ 45 \%$ for a KRAS mutation, which is in the same range as found in earlier studies of Chinese and Western CRC patients $[3,27]$. The distribution of KRAS mutations in the Western population showed that G12D was the most frequent mutation subtype in codon 12 , followed by $\mathrm{G} 12 \mathrm{~V} / \mathrm{C} / \mathrm{S} / \mathrm{A} / \mathrm{R}$ or $\mathrm{G} 12 \mathrm{~V} / \mathrm{S} / \mathrm{C} / \mathrm{A} / \mathrm{R}[27,36]$. In contrast, the corresponding order of KRAS codon 12 mutation frequency in our data was $\mathrm{G} 12 \mathrm{D} / \mathrm{V} / \mathrm{A} / \mathrm{C} / \mathrm{S} / \mathrm{R}$, as was found in another study of Chinese CRC patients [31]. For codon 13, the order of two mutation subtypes ( $38 \mathrm{G}>\mathrm{A}$ and $37 \mathrm{G}>\mathrm{T}$ ) was not different from that found by others. The BRAF mutation frequency in CRC patients from Western countries is 10$15 \%$ [37-39]. In our study, the BRAF mutation frequency was $\sim 4 \%$, that is, in the same range as in Japanese and other Chinese reports from different regions including Taiwan (1-7\%) [13,24,28,31]. This finding suggests that the $B R A F$ mutation frequency in Asian CRC patients is lower than in Western patients.

The PIK3CA gene encodes the P110 catalytic subunit of PI3K that regulates the pathway. In agreement with earlier studies, the PIK3CA mutation frequency was $\sim 12 \%$ in our samples and could co-occur with KRAS or $B R A F$ mutations $[21,37,40]$. And, in the 17 cases with concomitant mutations, 16 of them had PIK3CA and KRAS mutations $(\mathrm{P}=0.075)$, while only one case had PIK $3 C A$ and BRAF mutations. The concomitant occurrence of $P I K 3 C A$ and $K R A S$ mutations was reported previously in CRC and other human cancer types $[21,35]$. The coexistence of KRAS and BRAF mutations was not observed in our patient cohort, consistent with earlier studies. The mutual exclusive occurrence of $K R A S$ and $B R A F$ mutations suggests they occur in different tumor subtypes [12].

We also investigated the clinicopathological characteristics of CRC patients with respect to KRAS, BRAF, PIK3CA mutations. We found that the frequencies of $B R A F$ and PIK3CA mutations were significantly lower in rectal than in colon cancer. A lower frequency in rectal cancer was also observed in a few Western studies [35]. This observation emphasizes the difference between colon and rectal cancers, which may result in distinct treatment responses and prognosis $[41,42]$.

In this Chinese cohort of 126 sporadic colon cancer patients, we found that the BRAF V600E mutation was significantly associated with a higher metastatic rate and a poorer OS. In the multivariate analysis, $B R A F \mathrm{~V} 600 \mathrm{E}$ was an independent prognostic factor for OS in colon cancer, next to sex and TNM (Table 6). Actually, together with another case harboring a BRAF K601E mutation, BRAF mutations was also associated with a poorer OS (log rank, $\mathrm{P}=0.002$, data not shown) in our study cohort. It has been

Table 8 Analysis of OS according to the 3 most common KRAS codon 12 and 13 mutations in 205 BRAF wt colorectal cancer patients by cox regression analysis

\begin{tabular}{|c|c|c|c|c|c|c|c|}
\hline \multirow[b]{2}{*}{ KRAS } & \multirow[b]{2}{*}{$B R A F$} & \multirow[b]{2}{*}{ Total N } & \multirow[b]{2}{*}{ No. of events } & \multicolumn{2}{|c|}{ Univariate analysis } & \multicolumn{2}{|c|}{ Multivariate analysis } \\
\hline & & & & HR (95\% Cl) & $P$ & HR (95\% Cl) & $P$ \\
\hline$\overline{w t}$ & wt & 109 & 22 & 1 & & 1 & \\
\hline c. $38 \mathrm{G}>\mathrm{A}$ & wt & 23 & 9 & $2.4(1.1-5.3)$ & 0.026 & $2.6(1.2-5.8)$ & 0.016 \\
\hline$c .35 G>A$ & wt & 34 & 9 & $1.4(0.6-3.0)$ & 0.425 & $1.1(0.5-2.4)$ & 0.853 \\
\hline c.35G > T & wt & 20 & 5 & $1.4(0.5-3.6)$ & 0.546 & $1.5(0.6-4.0)$ & 0.408 \\
\hline
\end{tabular}

NOTE: The multivariate cox regression model included the same set of covariates selected in Table 7. P-values $\leq 0.05$ are in bold. 
well recognized that BRAF V600E mutation confers a poor prognosis in Western CRC patients $[9,10,12,13]$. However, among the limited number of $B R A F$ mutation studies in Chinese patients, only one study performed a survival analysis in a sample of 314 patients, including colon and rectum cancers. Although they reported the same conclusion as we do, they did not clarify which mutation types contributed to this effect [26]. As our patients were treated with the same chemotherapy and none of them received targeted therapy after surgery, our result may be interpreted as that the BRAF V600E mutation is a sensitive prognostic indicator independent of treatment regimen and disease progression. Obviously, this observation needs to be confirmed in a larger population of Chinese patients. Nevertheless, our findings suggest that prospective evaluation of the BRAF mutation status is equally important in Chinese patients with colon cancer, even though its mutation frequency (4-7\%) is lower than Western patients and no effective therapy available. The manifest adverse effects of this mutation require more vigorous treatment and surveillance in this group of highrisk patients.

Another point worth noting was that sex was an independent predictor for prognosis in our colon cancer patients, with male patients being at a higher risk than female patients. Concordant with our conclusion, the study [43] which looked at the cumulative 10-year incidence and mortality of CRC among men at ages 50, 55, and 60 in US revealed that women reached equivalent levels of disease $4-8$ years later than men. This finding indicates the importance in the choice of age at initiation of CRC screening.

Although, the predictive role of KRAS mutation in adopting anti-EGFR antibody therapy has been well recognized, its prognostic value in survival remains controversial. This may be caused by different study size, patient selection, operation options, chemotherapy regimens, sample controlling, material characters, detection method and data analysis. Importantly, few studies realized that KRAS wt samples were mixed with $B R A F$ mutants, which strongly affects the prognostic value of $K R A S$ mutations $[13,14]$. In our study, the negative prognostic role of KRAS mutations emerged when BRAF mutant patients were separated from the KRAS wt patients (Figure 3C).

Only a small and very recent detailed analysis estimated the prognostic effect of KRAS mutations when codon 12 and 13 are counted separately $[13,14,20]$. The main finding of these clinical studies is that KRAS mutations in codon 13 confer a poorer prognosis and outcome on patients under standard chemotherapy. In agreement, our KM curves clearly demonstrated that OS in patients with KRAS codon 13 mutations, in particular, c.38G > A (p.G13D, the most frequent codon 13 mutation in our patients (23 out of 25) and in general [19]), was significantly worse than that in patients without KRAS and $B R A F$ mutations (Figure 3D\&E). KRAS codon 12 mutations, on the other hand, had no effect on patients' OS in our study. In both univariate and multivariate analysis, we further confirmed KRAS codon 13 (G13D) mutation as an independent negative prognostic factor for OS. Since our patients had only received standard chemotherapy and none of them had targeted medicine after resection, our findings support KRAS codon 13 (G13D) mutation as a prognostic biomarker in the natural process of colorectal cancer.

In contrast to the clinical findings, the in vitro studies suggested that KRAS codon 13 (G13D) mutations confer a weaker transforming capacity on cells than codon 12 mutations [20]. In addition, recent computational analysis revealed that KRAS protein with a mutation in codon 13 has a similar structure and dynamics as KRAS wt protein. Consequently, patients with this mutation could benefit from anti-EGFR antibody therapy [44]. In fact, several recent studies investigated the efficacy of anti-EGFR therapies for mutations in codon 13 and 12 separately [20] and reported improved PFS and OS for advanced CRC patients with the G13D mutation after receiving cetuximab alone or in combination with chemotherapy. Therefore, KRAS codon (G13D) may not only be a prognostic biomarker but may also be predictive for a positive response to anti-EGFR treatment.

The limitations of this study include its retrospective nature, relatively small sample size $(\mathrm{n}=214)$ and short follow-up time. Nevertheless, we have found that BRAF V600E and KRAS G13D mutations were associated with worse OS in Chinese CRC patients. Moreover, we did not obtain epigenetic status or microsatellite instability (MSI) data, which plays a role in CRCs. However, the frequency of $B R A F$ mutation is low in Chinese CRC patients, with only $9(\sim 4 \%)$ in the present study, so that further subgroup analysis was not feasible in this study. We are enlarging our sample size by recruiting CRC patients from other clinical centers and will have longer follow-up data for further analysis. Furthermore, additional mutations, including KRAS mutations beyond exon 2 and NRAS mutations, will be analyzed in our cohorts, since current studies based on Western CRC patients seem to suggest that they may be prognostic for outcome and predictive for the efficacy of anti-EGFR therapies [45], and few data is available on Chinese patients.

\section{Conclusion}

In conclusion, our study demonstrated the BRAF V600E mutation was an independent prognostic factor for colon cancer patients and was the first study on Chinese patients to find that KRAS codon 13 mutations (in particular, c.38G > A, p.G13D), but not codon 12 mutations, 
were associated with poor prognosis in $B R A F$ wild-type CRCs. A single mutation type may represent a distinct biologic effect and clinical implication [46], but also appears to convey benefit from a targeted therapy. Our findings show that molecular features in CRC patients are important to avoid confounding effects in future clinical trials.

\section{Additional file}

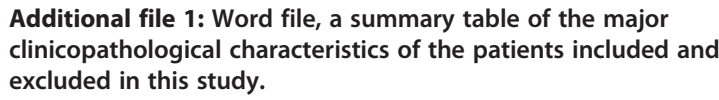

\section{Abbreviations}

Cl: Confidence interval; CRC: Colorectal cancer; FFPE: Formalin-fixed paraffinembedded; HR: Hazard ratio; KM method: Kaplan-Meier method; OS: Overall survival; wt: Wild-type.

\section{Competing interests}

The authors declare that they have no competing interests.

\section{Authors' contributions}

$\mathrm{YH}$ designed the study. JC, FG and $\mathrm{YH}$ conducted the experiments and data analysis. JC and $\mathrm{YH}$ interpreted the data and drafted the manuscript. XS, LZ and AZ helped with sample preparation, patients' data collection and interpretation. $\mathrm{HJ}$ helped the statistical analysis. All authors read and approved the final manuscript.

\section{Acknowledgements}

The authors thank Pathology and General Surgery departments of Zhongda Hospital affiliated to Southeast University for the preparation of the FFEP sections and the collection of the clinical data, and Professor Wouter $\mathrm{H}$ Lamers from University of Amsterdam for careful editing of the manuscript. This work was supported by the National Natural Science Foundation of China (81272400) and Research Fund for the Doctoral Program of Higher Education of China (20130092110052).

\section{Author details}

'Department of Pathogenic Biology and Immunology, Medical School of Southeast University, 87 Dingjiaoqiao, Nanjing 210009, Jiangsu, China. ${ }^{2}$ Department of Pathology, Zhongda Hospital Affiliated to Southeast University, Nanjing, Jiangsu, China. ${ }^{3}$ Department of General Surgery, Zhongda Hospital Affiliated to Southeast University, Nanjing, Jiangsu, China. ${ }^{4}$ Department of Epidemiology, School of Public Health, Southeast University, Nanjing, Jiangsu, China.

Received: 27 June 2014 Accepted: 17 October 2014

Published: 3 November 2014

\section{References}

1. Sung JJ, Lau JY, Young GP, Sano Y, Chiu HM, Byeon JS, Yeoh KG, Goh KL, Sollano J, Rerknimitr R, Matsuda T, Wu KC, Ng S, Leung SY, Makharia G, Chong VH, Ho KY, Brooks D, Lieberman DA, Chan FK: Asia Pacific consensus recommendations for colorectal cancer screening. Gut 2008, 57:1166-1176.

2. Gao J, Wang TT, Yu JW, Li YY, Shen L: Wild-type KRAS and BRAF could predict response to cetuximab in Chinese colorectal cancer patients. Chin J Cancer Res 2011, 23:271-275.

3. De Roock W, De Vriendt V, Normanno N, Ciardiello F, Tejpar S: KRAS, BRAF, PIK3CA, and PTEN mutations: implications for targeted therapies in metastatic colorectal cancer. Lancet Oncol 2011, 12:594-603.

4. Allegra CJ, Jessup JM, Somerfield MR, Hamilton SR, Hammond EH, Hayes DF, McAllister PK, Morton RF, Schilsky RL: American society of clinical oncology provisional clinical opinion: testing for KRAS gene mutations in patients with metastatic colorectal carcinoma to predict response to anti- epidermal growth factor receptor monoclonal antibody therapy. J Clin Oncol 2009, 27:2091-2096.

5. Van Cutsem E, Kohne CH, Lang I, Folprecht G, Nowacki MP, Cascinu S, Shchepotin I, Maurel J, Cunningham D, Tejpar S, Schlichting M, Zubel A, Celik I, Rougier P, Ciardiello F: Cetuximab plus irinotecan, fluorouracil, and leucovorin as first-line treatment for metastatic colorectal cancer: updated analysis of overall survival according to tumor KRAS and BRAF mutation status. J Clin Oncol 2011, 29:2011-2019.

6. Douillard JY, Siena S, Cassidy J, Tabernero J, Burkes R, Barugel M, Humblet Y, Bodoky G, Cunningham D, Jassem J, Rivera F, Kocakova I, Ruff P, BlasinskaMorawiec M, Smakal M, Canon JL, Rother M, Oliner KS, Wolf M, Gansert J: Randomized, phase III trial of panitumumab with infusional fluorouracil, leucovorin, and oxaliplatin (FOLFOX4) versus FOLFOX4 alone as first-line treatment in patients with previously untreated metastatic colorectal cancer: the PRIME study. J Clin Oncol 2010, 28:4697-4705.

7. Bokemeyer C, Bondarenko I, Makhson A, Hartmann JT, Aparicio J, de Braud F, Donea S, Ludwig H, Schuch G, Stroh C, Loos AH, Zubel A, Koralewski P: Fluorouracil, leucovorin, and oxaliplatin with and without cetuximab in the first-line treatment of metastatic colorectal cancer. J Clin Oncol 2009, 27:663-671.

8. Zlobec I, Bihl MP, Schwarb H, Terracciano L, Lugli A: Clinicopathological and protein characterization of BRAF- and K-RAS-mutated colorectal cancer and implications for prognosis. Int J Canc 2010, 127:367-380.

9. Farina-Sarasqueta A, van Lijnschoten G, Moerland E, Creemers GJ, Lemmens VE, Rutten HJ, van den Brule AJ: The BRAF V600E mutation is an independent prognostic factor for survival in stage II and stage III colon cancer patients. Ann Oncol 2010, 21:2396-2402.

10. Richman SD, Seymour MT, Chambers P, Elliott F, Daly CL, Meade AM, Taylor G, Barrett JH, Quirke P: KRAS and BRAF mutations in advanced colorecta cancer are associated with poor prognosis but do not preclude benefit from oxaliplatin or irinotecan: results from the MRC FOCUS trial. J Clin Oncol 2009, 27:5931-5937.

11. Ogino S, Meyerhardt JA, Irahara N, Niedzwiecki D, Hollis D, Saltz LB, Mayer RJ, Schaefer P, Whittom R, Hantel A, Benson AB, Goldberg RM, Bertagnolli $M M$, Fuchs CS: KRAS mutation in stage III colon cancer and clinical outcome following intergroup trial CALGB 89803. Clin Cancer Res 2009, 15:7322-7329.

12. Roth AD, Tejpar S, Delorenzi M, Yan P, Fiocca R, Klingbiel D, Dietrich D, Biesmans B, Bodoky G, Barone C, Aranda E, Nordlinger B, Cisar L, Labianca R, Cunningham D, Van Cutsem E, Bosman F: Prognostic role of KRAS and BRAF in stage II and III resected colon cancer: results of the translational study on the PETACC-3, EORTC 40993, SAKK 60-00 trial. J Clin Oncol 2010, 28:466-474.

13. Yokota T, Ura T, Shibata N, Takahari D, Shitara K, Nomura M, Kondo C, Mizota A, Utsunomiya S, Muro K, Yatabe Y: BRAF mutation is a powerful prognostic factor in advanced and recurrent colorectal cancer. $\mathrm{Br} J$ Cancer 2011, 104:856-862.

14. Imamura Y, Morikawa T, Liao X, Lochhead P, Kuchiba A, Yamauchi M, Qian ZR, Nishihara R, Meyerhardt JA, Haigis KM, Fuchs CS, Ogino S: Specific mutations in KRAS codons 12 and 13, and patient prognosis in 1075 BRAF wild-type colorectal cancers. Clin Cancer Res 2012, 18:4753-4763.

15. Guerrero S, Casanova I, Farre L, Mazo A, Capella G, Mangues R: K-ras codon 12 mutation induces higher level of resistance to apoptosis and predisposition to anchorage-independent growth than codon 13 mutation or proto-oncogene overexpression. Cancer Res 2000 60:6750-6756.

16. Samowitz WS, Curtin K, Schaffer D, Robertson M, Leppert M, Slattery ML: Relationship of Ki-ras mutations in colon cancers to tumor location, stage, and survival: a population-based study. Cancer Epidemiol Biomarkers Prev 2000, 9:1193-1197.

17. Andreyev HJ, Norman AR, Cunningham D, Oates J, Dix BR, lacopetta BJ, Young J, Walsh T, Ward R, Hawkins N, Beranek M, Jandik P, Benamouzig R, Jullian E, Laurent-Puig P, Olschwang S, Muller O, Hoffmann I, Rabes HM, Zietz C, Troungos C, Valavanis C, Yuen ST, Ho JW, Croke CT, O'Donoghue DP, Giaretti W, Rapallo A, Russo A, Bazan V, et al: Kirsten ras mutations in patients with colorectal cancer: the 'RASCAL II' study. Br J Cancer 2001, 85:692-696.

18. Bazan V, Migliavacca M, Zanna I, Tubiolo C, Grassi N, Latteri MA, La Farina M, Albanese I, Dardanoni G, Salerno S, Tomasino RM, Labianca R, Gebbia N, Russo A: Specific codon $13 \mathrm{~K}$-ras mutations are predictive of clinical outcome in colorectal cancer patients, whereas codon $12 \mathrm{~K}$-ras 
mutations are associated with mucinous histotype. Ann Oncol 2002, 13:1438-1446.

19. De Roock W, Jonker DJ, Di Nicolantonio F, Sartore-Bianchi A, Tu D, Siena S, Lamba S, Arena S, Frattini M, Piessevaux H, Van Cutsem E, O'Callaghan CJ, Khambata-Ford S, Zalcberg JR, Simes J, Karapetis CS, Bardelli A, Tejpar S: Association of KRAS p.G13D mutation with outcome in patients with chemotherapy-refractory metastatic colorectal cancer treated with cetuximab. JAMA 2010, 304:1812-1820.

20. Er TK, Chen CC, Bujanda L, Herreros-Villanueva M: Clinical relevance of KRAS mutations in codon 13: here are we? Cancer Lett 2014, 343:1-5.

21. Ogino S, Nosho K, Kirkner GJ, Shima K, Irahara N, Kure S, Chan AT, Engelman JA, Kraft P, Cantley LC, Giovannucci EL, Fuchs CS: PIK3CA mutation is associated with poor prognosis among patients with curatively resected colon cancer. J Clin Oncol 2009, 27:1477-1484.

22. Kato S, lida S, Higuchi T, Ishikawa T, Takagi Y, Yasuno M, Enomoto M, Uetake $\mathrm{H}$, Sugihara K: PIK3CA mutation is predictive of poor survival in patients with colorectal cancer. Int J Canc 2007, 121:1771-1778.

23. Sartore-Bianchi A, Martini M, Molinari F, Veronese S, Nichelatti M, Artale S, Di Nicolantonio F, Saletti P, De Dosso S, Mazzucchelli L, Frattini M, Siena S, Bardelli A: PIK3CA mutations in colorectal cancer are associated with clinical resistance to EGFR-targeted monoclonal antibodies. Cancer Res 2009, 69:1851-1857.

24. Li HT, LU YY, An YX, Wang X, Zhao QC: KRAS, BRAF and PIK3CA mutations in human colorectal cancer: relationship with metastatic colorectal cancer. Oncol Rep 2011, 25:1691-1697.

25. Shen H, Yuan Y, Hu HG, Zhong X, Ye XX, Li MD, Fang WJ, Zheng S: Clinical significance of K-ras and BRAF mutations in Chinese colorectal cancer patients. World J Gastroenterol 2011, 17:809-816.

26. Liou JM, Wu MS, Shun CT, Chiu HM, Chen MJ, Chen CC, Wang HP, Lin JT, Liang JT: Mutations in BRAF correlate with poor survival of colorectal cancers in Chinese population. Int J Color Dis 2011, 26:1387-1395.

27. Mao C, Zhou J, Yang Z, Huang Y, Wu X, Shen H, Tang J, Chen Q: KRAS, BRAF and PIK3CA mutations and the loss of PTEN expression in Chinese patients with colorectal cancer. PLoS One 2012, 7:e36653.

28. Hsieh LL, Er TK, Chen CC, Hsieh JS, Chang JG, Liu TC: Characteristics and prevalence of KRAS, BRAF, and PIK3CA mutations in colorectal cancer by high-resolution melting analysis in Taiwanese population. Clin Chim Acta 2012, 413:1605-1611.

29. Zhu YF, Yu BH, Li DL, Ke HL, Guo XZ, Xiao XY: PI3K expression and PIK3CA mutations are related to colorectal cancer metastases. World J Gastroenterol 2012, 18:3745-3751

30. Li Z, Chen Y, Wang D, Wang G, He L, Suo J: Detection of KRAS mutations and their associations with clinicopathological features and survival in Chinese colorectal cancer patients. J Int Med Res 2012, 40:1589-1598.

31. Shen Y, Wang J, Han X, Yang H, Wang S, Lin D, Shi Y: Effectors of epidermal growth factor receptor pathway: the genetic profiling ofKRAS, BRAF, PIK3CA, NRAS mutations in colorectal cancer characteristics and personalized medicine. PLoS One 2013, 8:e81628.

32. Pu X, Pan Z, Huang Y, Tian Y, Guo H, Wu L, He X, Chen X, Zhang S, Lin T: Comparison of KRAS/BRAF mutations between primary tumors and serum in colorectal cancer: biological and clinical implications. Oncol Lett 2013, 5:249-254

33. Wang J, Yang $H$, Shen $Y$, Wang S, Lin D, Ma L, Han X, Shi Y: Direct sequencing is a reliable assay with good clinical applicability for KRAS mutation testing in colorectal cancer. Cancer Biomark 2013, 13:89-97.

34. Chang YS, Chang SJ, Yeh KT, Lin TH, Chang JG: RAS, BRAF, and TP53 gene mutations in Taiwanese colorectal cancer patients. Onkologie 2013, 36:719-724.

35. He Y, Van't Veer $\sqcup$, Mikolajewska-Hanclich I, van Velthuysen ML, Zeestraten EC, Nagtegaal ID, van de Velde CJ, Marijnen CA: PIK3CA mutations predict local recurrences in rectal cancer patients. Clin Cancer Res 2009, 15:6956-6962

36. Vaughn CP, Zobell SD, Furtado LV, Baker CL, Samowitz WS: Frequency of KRAS, BRAF, and NRAS mutations in colorectal cancer. Genes Chromosomes Cancer 2011, 50:307-312.

37. De Roock W, Claes B, Bernasconi D, De Schutter J, Biesmans B, Fountzilas G, Kalogeras KT, Kotoula V, Papamichael D, Laurent-Puig P, Penault-Llorca F, Rougier P, Vincenzi B, Santini D, Tonini G, Cappuzzo F, Frattini M, Molinari F, Saletti P, De Dosso S, Martini M, Bardelli A, Siena S, Sartore-Bianchi A Tabernero J, Macarulla T, Di Fiore F, Gangloff AO, Ciardiello F, Pfeiffer P, et al: Effects of KRAS, BRAF, NRAS, and PIK3CA mutations on the efficacy of cetuximab plus chemotherapy in chemotherapy-refractory metastatic colorectal cancer: a retrospective consortium analysis. Lancet Oncol 2010, 11:753-762

38. Di Nicolantonio F, Martini M, Molinari F, Sartore-Bianchi A, Arena S, Saletti P, De Dosso S, Mazzucchelli L, Frattini M, Siena S, Bardelli A: Wild-type BRAF is required for response to panitumumab or cetuximab in metastatic colorectal cancer. J Clin Oncol 2008, 26:5705-5712.

39. Prahallad A, Sun C, Huang S, Di Nicolantonio F, Salazar R, Zecchin D, Beijersbergen RL, Bardelli A, Bernards R: Unresponsiveness of colon cancer to BRAF(V600E) inhibition through feedback activation of EGFR. Nature 2012, 483:100-103

40. Sartore-Bianchi A, Di Nicolantonio F, Nichelatti M, Molinari F, De Dosso S, Saletti P, Martini M, Cipani T, Marrapese G, Mazzucchelli L, Lamba S, Veronese S, Frattini M, Bardelli A, Siena S: Multi-determinants analysis of molecular alterations for predicting clinical benefit to EGFR-targeted monoclonal antibodies in colorectal cancer. PLOS One 2009, 4:e7287.

41. Sanz-Pamplona R, Cordero D, Berenguer A, Lejbkowicz F, Rennert H, Salazar R, Biondo S, Sanjuan X, Pujana MA, Rozek L, Giordano TJ, Ben-Izhak O, Cohen HI, Trougouboff P, Bejhar J, Sova Y, Rennert G, Gruber SB, Moreno V: Gene expression differences between colon and rectum tumors. Clin Cancer Res 2011, 17:7303-7312.

42. Phipps Al, Lindor NM, Jenkins MA, Baron JA, Win AK, Gallinger S, Gryfe R, Newcomb PA: Colon and rectal cancer survival by tumor location and microsatellite instability: the colon cancer family registry. Dis Colon Rectum 2013, 56:937-944.

43. Brenner $\mathrm{H}$, Hoffmeister $\mathrm{M}$, Arndt $\mathrm{V}$, Haug U: Gender differences in colorectal cancer: implications for age at initiation of screening. $\mathrm{Br} \mathrm{J}$ Cancer 2007, 96:828-831.

44. Chen CC, Er TK, Liu YY, Hwang JK, Barrio MJ, Rodrigo M, Garcia-Toro E, Herreros-Villanueva M: Computational analysis of KRAS mutations: implications for different effects on the KRAS p.G12D and p.G13D mutations. PLoS One 2013, 8:e55793.

45. Douillard JY, Oliner KS, Siena S, Tabernero J, Burkes R, Barugel M, Humblet $Y$, Bodoky G, Cunningham D, Jassem J, Rivera F, Kocakova I, Ruff P, BlasinskaMorawiec M, Smakal M, Canon JL, Rother M, Williams R, Rong A, Wiezorek J, Sidhu R, Patterson SD: Panitumumab-FOLFOX4 treatment and RAS mutations in colorectal cancer. N Engl J Med 2013, 369:1023-1034.

46. Ogino S, Fuchs CS, Giovannucci E: How many molecular subtypes? Implications of the unique tumor principle in personalized medicine. Expert Rev Mol Diagn 2012, 12:621-628.

doi:10.1186/1471-2407-14-802

Cite this article as: Chen et al:: BRAF V600E mutation and KRAS codon 13 mutations predict poor survival in Chinese colorectal cancer patients. BMC Cancer 2014 14:802.

\section{Submit your next manuscript to BioMed Central and take full advantage of:}

- Convenient online submission

- Thorough peer review

- No space constraints or color figure charges

- Immediate publication on acceptance

- Inclusion in PubMed, CAS, Scopus and Google Scholar

- Research which is freely available for redistribution 